\title{
Welcome Message
}

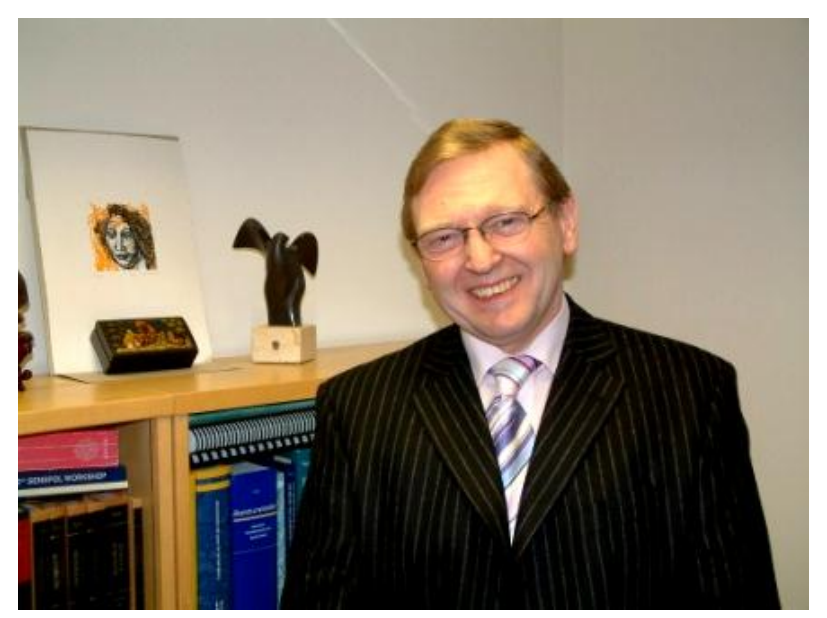

Professor Anthony P. F. Turner, PhD, DSc, FRSC

\section{Dear Readers,}

I am delighted to welcome you to the first issue of Advanced Materials Letters published by VBRI press. Publishing periodically undergoes small revolutions and we can see a plethora of activities at the current time, which are attempting to satisfy the voracious appetite of rapidly expanding sectors. Advanced Materials is one such area where advances in molecular science, chemistry and engineering are furnishing multifarious opportunities that will underpin new products and process for a wide variety of applications in medicine, the food industry, environmental materials and microfabrication. Such facilitating science is essential for the development of emerging areas such as plastic electronics, bionics, synthetic biology, energy harvesting and biodegradable materials. This vehicle will facilitate the open exchange of techniques and methodologies designed to bridge traditional disciplines and to harness the energies of scientists world-wide in delivering novel materials for a new age of biomimetic materials, composites and supramolecular systems. I look forward to reading many exciting articles concerning the structure, synthesis, characterisation and application of the materials that will form the building blocks of new industry and to looking back in the future to a milestone in the publication and promotion of this essential technology. I am confident, that in time Advanced Materials Letters will serve the scientific community well and become one of the prominent journals in the 'materials science' field in future.

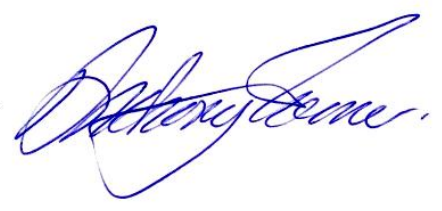

Professor Anthony P.F. Turner PhD, DSc, FRSC

Honorary Editor \& Distinguished Professor of Biotechnology, Cranfield University, $U K$ 